\title{
Isolasi Senyawa Sesquiterpen Dari Fraksi Aktif Antibakteri Alga Laut Merah Laurencia tronoi
}

\author{
Verly Dotulong, Lena J. Damongilala dan Lita A. D. Y. Montolalu \\ Program Studi Teknologi Hasil Perikanan \\ Fakultas Perikanan dan Ilmu Kelautan, Universitas Sam Ratulangi. \\ Jl. Kampus Unsrat Bahu, Manado 95115, Sulawesi Utara, Indonesia. \\ *Penulis Korespondensi: verly dotulong@unsrat.ac.id \\ (Diterima 14-10-2020; Direvisi 07-01-2021; Dipublikasi 15-01-2021)
}

\begin{abstract}
The purpose of this study was to obtain new compounds isolated from the active antibacterial fraction, namely the hexane fraction of the red marine algae Laurencia tronoi, so that these marine algae can be developed as functional foods. The extraction method used was maceration with methanol-water $50 \%$. The water methanol extract was continuously fractionated using $n$-hexane, ethyl acetate and water as solvents. The n-hexane fraction which has the highest antibacterial activity is then purified to obtain pure isolates using 3 steps column chromatography. Detection of the separation results at each stage was carried out using thin layer chromatography. The separation of stages 1 and 2 used a stationary phase of silica gel $60 F_{254}$ and a mobile phase of hexane-ethylacetate, while the separation of the third stage used a stationary phase of silica gel $60 F_{254} R P-18$ and a mobile phase of water-methanol to obtain pure isolates. Structural characterization of pure isolates using the NMR spectroscopic method. The pure isolate produced is in the form of a white amorphous solid with the results of interpretation of the $H$-NMR, C-NMR, DEPT, HMQC, HMBC and COSY spectrum which is a sesquiterpene compound having the molecular formula $\mathrm{C}_{15} \mathrm{H}_{26} \mathrm{O}_{4}$ having the name IUPAC 3,3,9a-trimethyl-6-metylene-decahydro-1 $\mathrm{H}$ benzo [7] annulen-1,2,4a, 8-tetraol. This pure isolate is thought to be a new compound because based on literatur tracing, the same structure as the pure isolate produced in this study has not been found.
\end{abstract}

Keywords: Laurencia tronoi, new compound, sesquiterpenes.

Tujuan penelitian ini adalah mendapatkan senyawa baru yang diisolasi dari fraksi aktif antibakteri yaitu fraksi heksana alga laut merah Laurencia tronoi, sehingga alga laut ini dapat dikembangkan sebagai pangan fungsional. Metode ekstraksi yang digunakan adalah maserasi dengan metanol-air 50\%, Pada ekstrak metanol air dilakukan fraksinasi berkesinambungan dengan menggunakan pelarut n-heksana, etilasetat dan air. Fraksi n-heksana yang mempunyai aktivitas antibakteri tertinggi selanjutnya dimurnikan untuk mendapatkan isolat murni dengan menggunakan kromatografi kolom sebanyak 3 tahap. Pendeteksian hasil pemisahan pada tiap tahap dilakukan dengan menggunakan kromatografi lapis tipis. Pemisahan tahap 1 dan 2 menggunakan fasa diam silika gel $60 \mathrm{~F}_{254}$ dan fasa gerak heksana-etilasetat, sedangkan pemisahan tahap ke-3 menggunakan fasa diam silika gel $60 \mathrm{~F}_{254} \mathrm{RP}-$ 18 dan fasa gerak air-metanol hingga didapatkan isolat murni. Karakterisasi struktur isolat murni menggunakan metode spektrokopi NMR. Isolat murni yang dihasilkan berupa padatan amorf berwarna putih dengan hasil interpretasi terhadap spectrum H-NMR, C-NMR, DEPT, HMQC, HMBC dan COSY adalah termasuk golongan senyawa sesquiterpen mempunyai rumus molekul $\mathrm{C}_{15} \mathrm{H}_{26} \mathrm{O}_{4}$ mempunyai nama IUPAC 3,3,9a-trimetil-6-metilen-dekahidro-1H-benzo[7] annulen-1,2,4a,8-tetraol. Isolat murni ini diduga adalah senyawa baru karena berdasarkan penelusuran literatur belum ditemukan struktur yang sama dengan struktur isolat murni yang dihasilkan dalam penelitian ini.

Kata kunci: Laurencia tronoi, senyawa baru, sesquiterpen.

\section{PENDAHULUAN}

Rumput laut merah genus Laurencia sebagian besar berada di perairan tropis dan subtropis (Abde-Mageed et al., 2010), telah terbukti menjadi sumber yang kaya metabolit sekunder terutama sesquiterpen, dimana banyak dari metabolit sekunder ini telah dilaporkan memiliki berbagai aktivitas biologis seperti anti mikroba, anti feedant dan kegiatan sitotoksik (Su et al., 2009). Laurencia sp. selain berfungsi sebagai bahan makanan sumber karagenan juga mengandung senyawa terpenoida yang mempunyai bioaktivitas sebagai anti jamur, anti bakteri, anti kanker, anti proliferatif (Trono, 1988; Dawes, 1990; Yun-Ji et al., 2008; Su et al., 2009).

Yun-Ji et al. (2008) mengisolasi 7 senyawa terpen dari alga laut Laurencia saitoi yaitu komponen 15-bromo-2,7,19-triacetoxyparguer-9(11)-en-16-ol (1), 15-bromo-2,7,16,19tetraacetoxypargue-9(11)-ene (2), 15-bromo-2,19-diacetoxyparguer-9(11)-en-7,16-diol (3), 15 - 
bromo-2,16,19-triacetoxyparguer-9(11)-en-7-ol (4), 15-bromo-2,16-diacetoxyparguer-9(11)-en-7ol (5), 15-bromoparguer-9(11)-en-16-ol (6), 15-Bromoparguer-7-en-16-ol (7). Su et al. (2009) berhasil mengisolasi sequiterpen yang mengandung $\mathrm{Br}$ dari alga laut Laurencia similis yaitu isopalisol $\left(\mathrm{C}_{15} \mathrm{H}_{23} \mathrm{BrO}\right)$, lusenensol $\left(\mathrm{C}_{15} \mathrm{H}_{24} \mathrm{Br}_{2} \mathrm{O}\right)$, palisadin $\mathrm{B}\left(\mathrm{C}_{15} \mathrm{H}_{24} \mathrm{OBr}_{2}\right)$, aplisistatin $\mathrm{C}$ $\left(\mathrm{C}_{15} \mathrm{H}_{2} 1 \mathrm{BrO}_{3}\right)$, palisadin $\mathrm{A}\left(\mathrm{C}_{15} \mathrm{H}_{23} \mathrm{BrO}_{2}\right)$ dan hidroksil palisadin $\mathrm{C}\left(\mathrm{C}_{15} \mathrm{H}_{24} \mathrm{Br}_{2} \mathrm{O}_{2}\right)$ beberapa diantaranya berfungsi sebagai anti kanker. Elatol adalah suatu sesquiterpen yang mengandung $\mathrm{Br}$ diisolasi dari Laurencia dendroydae, yang diawali dengan ekstraksi dengan n-heksana, menunjukkan kemampuannya sebagai agen antiproliferatif yang ampuh dan antileishmanial (Santos et al, 2010). Shui-Chun and Yue-Wei (2010), telah mengisolasi 9 sesquiterpen dari Laurencia okamurai yang diawali dengan ekstraksi menggunakan aseton, yaitu: debromoaplysinol, bromoaplysinol aplysinol acetate, debromoi-solaurinterol, isolaurinterol, filiformin , $\alpha$ isobromocuparene, cuparene-type ether dan deoxyprepacifenol, proses isolasi diawali dengan mengekstraksi menggunakan aseton selanjutnya ekstrak kasar aseton dipartisi dengan larutan etanol- air. Dari penelitian-penelitian ini dapat dilihat bahwa baik proses isolasi maupun struktur sesquiterpen yang diisolasi berbeda dengan struktur sesquiterpen dari hasil penelitian ini, sehingga penelitian ini memiliki tingkat kebaharuan yang tinggi.

Adapun tujuan dari penelitian ini adalah mendapatkan senyawa baru yang diisolasi dari fraksi aktif antibakteri yaitu fraksi heksana alga laut merah Laurencia tronoi.

\section{MATERIAL DAN METODE}

Penelitian ini bersifat eksploratif untuk mendapatkan senyawa kimia baru dari fraksi aktif anti bakteri rumput laut merah $L$. tronoi yaitu fraksi heksana. Sampel rumput laut diambil di perairan Pulau Nain, Kabupaten Minahasa Utara, Provinsi Sulawesi Utara.

Sebelum proses ekstraksi terlebih dahulu sampel dikeringkan selanjutnya dikemas dalam plastik. Prosedur ekstraksi mengikuti Dotulong et al. (2013) adalah sebagai berikut: bubuk alga laut merah $L$. tronoi kering diekstraksi dengan metode maserasi menggunakan pelarut metanol-air $50 \% \mathrm{v} / \mathrm{v}$. Ekstrak metanol selanjutnya partisi bertingkat menggunakan pelarut $\mathrm{n}$-heksana, etilaset dan air. Ekstrak metanol dan fraksi-fraksi yang diperoleh diukur aktivitas antibakteri (diameter zona hambat) (Dotulong et al., 2016). Dari hasil pengukuran diperoleh bahwa fraksi $\mathrm{n}$-heksana mempunyai aktivitas anti bakteri tertinggi, sehingga fraksi n-heksana inilah yang dipilih untuk diisolasi senyawa aktif anti bakteri.

Proses isolasi/pemurnian menurut Harborne (2006) adalah sebagai berikut: fraksi n-heksana L. tronoi sebanyak $1 \mathrm{~g}$ dipisahkan dengan menggunakan 2 jenis kromatografi kolom (KK) yaitu fasa diam silika gel $60 \mathrm{~F}_{254}$ dan fasa gerak heksana-etilasetat serta fasa diam silika gel $60 \mathrm{~F}_{254}-\mathrm{RP}-18$ dan fasa gerak air-metanol, deteksi hasil pemisahan menggunakan kromatografi lapis tipis (KLT). Setelah ditemukan senyawa murni dengan cara deteksi hasil pemisahan dari KK pada KLT. Selanjutnya dilakukan elusidasi struktur senyawa murni menggunakan spektroslopi NMR (Nuclear magnetic Resonance) merk JEOL tipe ECA-500 MHz. yaitu H-NMR, Cosy, C-NMR, C dua dimensi (DEPT, HMBC, HMQC) (Soepratman, 2010). Data spektrum NMR selanjutnya diinterpretasi untuk mendapatkan struktur dari isolat dan nama IUPAC dari isolat murni tersebut.

\section{HASIL DAN PEMBAHASAN}

Ekstrak n-heksana L. tronoi yang diberi kode f-H ditempatkan pada kolom kromatografi yang mempunyai diameter $(\mathrm{d})$ dan tinggi $(\mathrm{t}) \rightarrow(\mathrm{d}: 1,5 \mathrm{~cm} ; \mathrm{t}: 65 \mathrm{~cm})$ dengan perbandingan ekstrak dengan silika gel 1:20, dilakukan elusi secara bergradien dengan menggunakan eluen n-heksanaetilasetat diperoleh 23 fraksi yang diberi kode f-H-1 s/d f-H-23, Selanjutnya fraksi fH-6 yang mempunyai massa yang cukup yang diisolasi lanjut untuk mencari senyawa murni.

Penelusuran isolat murni dilakukan pada fraksi f-H-6 dengan massa 105,9mg, alasan dipilihnya fraksi ini untuk ditelusuri lebih lanjut adalah karena terdapat lebih sedikit jumlah spot/komponen yang dibandingkan dengan fraksi lainnya. Selanjutnya dilakukan pemisahan pada kromatografi lapis tipis, ditemukan pemisahan senyawa terbaik pada fasa diam silica gel dan fasa gerak heksana-etilastat 8:2. Fraksi f-H-6 selanjutnya dipisahkan dengan dikromatografi kolom gravitasi $(\mathrm{d}=0,8 \mathrm{~cm}, \mathrm{t}=60 \mathrm{~cm})$, menggunakan fasa diam silika gel dan fasa gerak heksana-etilasetat 
gradient $1 \%$ secara bertahap menghasilkan 30 fraksi (f-H-6-1 s/d f-H-6-30), dari 30 fraksi yang dihasilkan dipilih fraksi f-H-6-7 dengan massa 31,5 mg untuk diisolasi lebih lanjut.

Fraksi fH-6-7 dengan berat 31,5mg dikromatografi kolom dengan fasa diam Silika Gel $\mathrm{F}_{60}{ }_{254} \mathrm{RP} 18$ dan dielusi dengan air -metanol gradien 1\%. Hasil elusi didapatkan sub fraksi FH-6-71 sampai dengan FH-6-7-14. Isolat murni ditemukan pada sub fraksi FH-6-7-11. Gambar 1 menunjukkan noda atau spot isolat murni pada kromatografi lapis tipis (KLT) dengan fasa diam silika gel $60 \mathrm{~F}_{234}-\mathrm{RP} 18$ dan fasa gerak metanol-air 8:2.

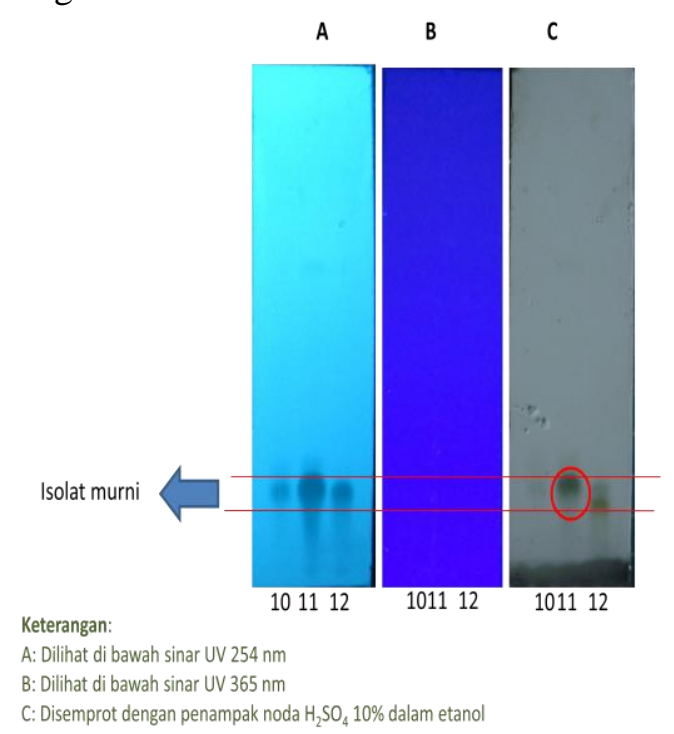

Gambar 1. KLT f 6-7-10 s/d f 6-7-12 dengan pelarut metanol-air (8:2).

Ringkasan frakmentasi senyawa, struktur isolat dengan korelasi COSY dan HMBC, struktur senyawa berdasarkan penomoran IUPAC serta struktur isolat murni ditampilkan pada Gambar 2, 3, 4 dan 5.

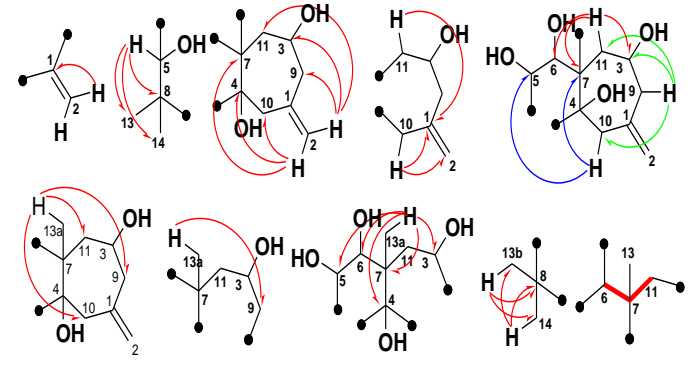

Gambar 2. Fragmen-fragmen isolat murni.

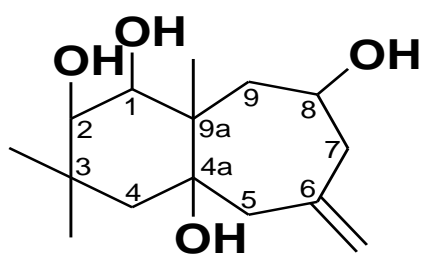

Gambar 4. Penomoran Senyawa berdasarkan Gambar 5. Struktur Isolat murni. aturan IUPAC

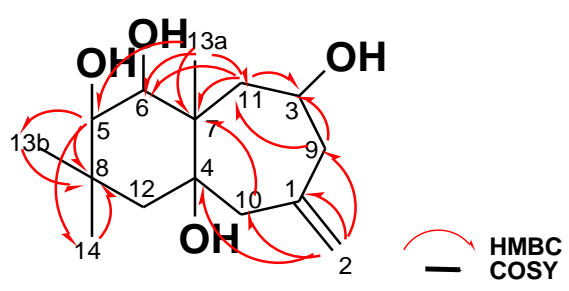

Gambar 3. Struktur Isolat dengan korelasi COSY dan HMBC.

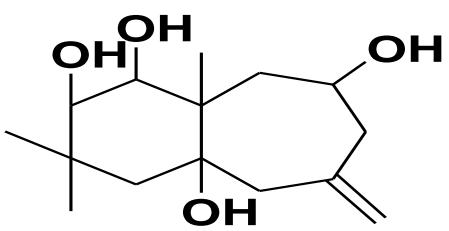

Isolat murni yang dihasilkan berupa padatan amorf berwarna putih dengan massa fraksi sebesar 5mg, dilarutkan dalam metanol, kemudian dielusidasi struktur senyawanya dengan menggunakan spektroskopi C-NMR, H-NMR, dan 2D-NMR( DEPT 135 , HMQC HMBC dan COSY). 
Nilai dan ringkasan data pergeseran kimia 1H-, 13C- dan 2D-NMR senyawa murni ditampilkan pada Tabel 1, dan konversi nomor karbon terhadap posisi karbon pada struktur senyawa dapat dilihat pada Tabel 2.

Tabel 1. Data pergeseran kimia1H-, 13C- dan 2D-NMR senyawa hasil isolasi.

\begin{tabular}{|c|c|c|c|c|}
\hline No & $\delta_{\mathrm{C}} 125 \mathrm{MHz}(\mathrm{ppm})$ & $\delta_{\mathrm{H}}($ Int., mult., $J=\mathrm{Hz}) 500 \mathrm{MHz}$ (ppm) & HMBC & COSY \\
\hline 1 & 141,2 & - & $\mathrm{H}-2, \mathrm{H}-10, \mathrm{H}-11$ & - \\
\hline 2 & 118,0 & $\begin{array}{l}5,38(1 \mathrm{H} ; s) \\
5,05(1 \mathrm{H} ; s)\end{array}$ & $\mathrm{H}-10$ & - \\
\hline 3 & 72,2 & $4,12(1 \mathrm{H} ; b s)$ & H-2, H-9, H-11 & - \\
\hline 4 & 71,9 & - & $\mathrm{H}-2, \mathrm{H}-9, \mathrm{H}-11, \mathrm{H}-13$ & - \\
\hline 5 & 70,3 & $4,47(1 \mathrm{H} ; d ; 3,25)$ & $\mathrm{H}-10, \mathrm{H}-13$ & - \\
\hline 6 & 61,2 & $4,72(1 \mathrm{H} ; b s)$ & $\mathrm{H}-9, \mathrm{H}-11, \mathrm{H}-13$ & $\mathrm{H}-11$ \\
\hline 7 & 51,2 & - & H-2, H-9, H-10, H-11, H-13 & - \\
\hline 8 & 44,3 & - & H-5, H-11, H-13, H-14 & - \\
\hline 9 & 38,9 & $2,20-2,16(2 \mathrm{H})$ & $\mathrm{H}-2, \mathrm{H}-9, \mathrm{H}-13$ & - \\
\hline 10 & 38,7 & $2,50(2 \mathrm{H} ; d ;)$ & $\mathrm{H}-2, \mathrm{H}-9, \mathrm{H}-13$ & - \\
\hline 11 & 38,6 & $\begin{array}{c}2,62(1 \mathrm{H} ; d ;) \\
2,09(1 \mathrm{H} ; t ;)\end{array}$ & $\mathrm{H}-2, \mathrm{H}-9, \mathrm{H}-13$ & H-6 \\
\hline 12 & 25,7 & $1,92(2 \mathrm{H} ; d d ;)$ & - & - \\
\hline $\begin{array}{l}13 a \\
13 b\end{array}$ & 24,3 & $\begin{array}{l}1,70(3 \mathrm{H} ; \mathrm{s}) \\
1,08(3 \mathrm{H} ; \mathrm{s})\end{array}$ & $\mathrm{H}-5$ & - \\
\hline 14 & 20,7 & $1,08(3 \mathrm{H} ; \mathrm{s})$ & $\mathrm{H}-5$ & - \\
\hline
\end{tabular}

Tabel 2. Konversi nomor karbon terhadap posisi karbon dalam struktur senyawa.

\begin{tabular}{ccc}
\hline No & Posisi Pada Penomoran & $\boldsymbol{\delta}_{\mathbf{C}} \mathbf{1 2 5} \mathbf{M H z} \mathbf{( p p m )}$ \\
\hline 1 & 6 & 141,2 \\
2 & $6-\mathrm{CH}_{2}$ & 118,0 \\
3 & 8 & 72,2 \\
4 & $4 \mathrm{a}$ & 71,9 \\
5 & 2 & 70,3 \\
6 & 1 & 61,2 \\
7 & $9 \mathrm{a}$ & 51,2 \\
8 & 3 & 44,3 \\
9 & 7 & 38,9 \\
10 & 5 & 38,7 \\
11 & 9 & 38,6 \\
12 & 4 & 25,7 \\
$13 \mathrm{a}$ & $9 \mathrm{a}$ & 24,3 \\
$13 \mathrm{~b}$ & $9 \mathrm{a}-\mathrm{CH}_{3}$ & 24,3 \\
14 & $3-\mathrm{CH}_{3}$ & 20,7 \\
\hline
\end{tabular}

Senyawa murni yang dihasilkan mempunyai rumus molekul $\mathrm{C}_{15} \mathrm{H}_{26} \mathrm{O}_{4}$ memiliki nilai DBE 3 yang berasal dari dua buah siklik dan satu buah ikatan rangkap dua diduga merupakan senyawa golongan sesquiterpen yang bernama 3,3,9a-trimetil-6-metilen-dekahidro-1H-benzo[7]annulen1,2,4a,8-tetraol.

\section{KESIMPULAN}

Kesimpulan yang dapat ditarik dari hasil penelitian adalah sebagai berikut: sesquiterpen ini dihasilkan melalui serangkaian tahap yaitu ekstraksi dengan metanol air 50\% pada bubuk rumput laut merah Laurencia tronoi, dilanjutkan dengan fraksinasi berkesinambungan dengan hekasan, etilasetat dan air, isolasi dan karakterisasi struktur isolat murni dilakukan pada fraksi aktif antibakteri yaitu fraksi heksana. Isolat murni yang dihasilkan berupa padatan amorf berwarna putih dari golongan sesquiterpen yang bernama 3,3,9a-trimetil-6-metilen-dekahidro-1Hbenzo[7]annulen-1,2,4a,8-tetraol. 


\section{DAFTAR PUSTAKA}

Dawes C.J. 1998. Marine Botany. Second Edition. John Wiley and Sons, Inc.

Dotulong V, Widjanarko S.B, Yunianta and Mamahit L.P. 2013. The Content of Total Phenol and Antoxidant Activity Three Types Sea Algae Taken at the North Sulawesi Waters. Food Science and Quality Management ISSN 2224 6088 (Paper) ISSN 2225-0557 (Online) www.iiste.org 40 Vol.17.

Dotulong V, Wonggo D, Montolalu L.A.D.Y., dan Damongilala L. J. 2016. Potensi Antibakteri rumput laut Laurencia tronoi Asal Perairan Sulawesi Utara .Prociding Nasional MPHPI dan Pertemuan Ilmiah Tahunan Ke-8. Di Ambon, ISBN: 978-602-61551-0-8.

Harborne. J.B. 2006. Metode Fitokimia. Penuntun Cara Modern Menganalisis Tumbuhan. Terbitan Kedua. Penerjemah:Kosasih Padmawinata dan Iwang Soediro. Penyunting: Sofia Mansoor. ITB Bandung.

Santos A.O.D., P.V. Santos, Tânia, Ueda-Nakamura T.U, B.P.D. Filho, D.B. Sudatti, É.M Bianco , R.C. Pereira, and C.V. Nakamura. 2010. Effect of Elatol, Isolated from Red Seaweed Laurencia dendroidea, on Leishmania amazonensis. Mar. Drugs 2010, 8, 2733-2743.

Shui-Chun M, and G. Yue-Wei. 2010. Sesquiterpenes from Chinese Red Alga Laurencia okamurai. Chinese Journal of Natural Medicines 8(5): 0321-0325

Soepratman. 2010. Elusidasi Struktur Senyawa Organik. FMIPA Universitas Pajajaran. Bandung.

Su H, D.Y. Si, J. Li, S.Y. Cuo, L. Lili, Z.H, Yuan, and X. Binzhu. 2009. Sesquiterpen From Laurencia cimilis. Molecules 14(1889-1897) ISSN 1420-3049.

Trono 1988. Philipine Seaweed. Philipine National Book Store Inc Pub Metro. Manila.

Yun Ji. N, X. Ming Li, and Gui Wang. B. 2008. Halogenated Terpenes and a C15-Acetogenin from the Marine Red Alga Laurencia saitoi. Molecules 13, 2894-2899. 